\title{
“SE O DEBATE ACADÊMICO REDUZIR-SE A UMA QUESTÃO APENAS QUANTITATIVA (O QUANTO PUBLICAMOS, OS ÍNDICES E RANKINGS) ESTAMOS DECRETANDO 0 FIM DA INOVAÇÃO NO PENSAMENTO ACADÊMICO".
}

\author{
Entrevista com Nizar Messari ${ }^{1}$
}

\section{Revista Malala (RM)}

Professor Nizar, em linhas gerais, como o senhor avalia esse universo de pesquisa sobre o Oriente Médio e mundo muçulmano, pensando a partir do Brasil?

\section{Nizar Messari (NM)}

Acho que há um interesse pelo assunto, um interesse que existe de maneira geral pela população brasileira, pela opinião pública brasileira sobre o mundo árabe e muçulmano. Mas não existe grande interesse acadêmico pela área. Eu me lembro que todas as vezes que tentei oferecer cursos de mestrado e doutorado sobre questões de mundo árabe e muçulmano a resposta era muito pequena. Enquanto toda vez que eu era convidado para uma palestra ou quando eu dava um curso de extensão sobre esse assunto, a audiência era sempre muito grande e muito interessada. Então me parece que o interesse é mais de curiosidade e menos propriamente acadêmico. Existem, no entanto, alguns focos ou algumas instituições que demonstram mais interesse. Como acontece com outras áreas de estudos nas universidades brasileiras, esse interesse é mais sobre como o Brasil se relaciona com essas áreas e regiões. Na parte Luso-Africana, por exemplo, o interesse é pensar como o Brasil se relaciona com esta parte do continente. De forma mais ampla no Mundo Árabe, o interesse é por como o Brasil se posiciona e se relaciona em termos de política externa e comércio internacional. Poucos pensam na região ou na área geográfica propriamente e como objeto de estudo.

\section{RM}

O senhor não acha que há um recorte a partir de 11 de Setembro? Porque a impressão que se tem é que com o 11 de Setembro - com a questão do terrorismo, digamos, toda aquela repercussão que o atentado teve - abriu-se todo um campo de pesquisa ligado ao terrorismo, a relação entre o fenômeno e o Islã, fundamentalismo e etc. Havia antes um outro tipo de pesquisa, mas depois deste atentado o estudo passou a ter mais esse formato das Relações Internacionais. 0 que o senhor acha?

\footnotetext{
${ }^{1}$ Professor e pesquisador decano da School of Humanities \& Social Sciences da Al Akhawayn University, no Marrocos. Entrevista realizada por Skype no dia 07/02/2017 com Ariel Finguerut e Cila Lima, membros do Conselho Editorial da Revista Malala.
} 


\section{NM}

Esse interesse e suposto elo que se estabelece entre o Islã e o terrorismo, a mim pessoalmente me incomoda. Eu entendi sua pergunta sobre a virada que representou 11 de Setembro, mas justamente, se o que vamos chamar de interesse pelo mundo árabe e muçulmano é essa relação que se estabelece entre o Islã e o terrorismo, me parece que de novo é um interesse derivado, que não se estuda o mundo árabe e muçulmano por si, mas sim como essa ameaça ao Ocidente - ou ameaça a estabilidade internacional. Não se procura estudar a história do mundo árabe, as relações sociais no seio dos países árabes muçulmanos, não se estuda a questão do gênero neste mundo árabe muçulmano; se estuda como esse mundo árabe muçulmano produz uma ameaça para o Ocidente. De novo então uma relação derivada e não um estudo do mundo árabe por si só. Por outro lado, depois do 11 de Setembro, teve justamente esse interesse específico pelo mundo muçulmano, mas me parece que não é algo que tenha ficado. 0 efeito do 11 de Setembro não foi um efeito duradouro no mundo acadêmico, até em termos de estudos das questões de segurança internacional. Da mesma forma, a Primavera Árabe não teve um impacto duradouro sobre a agenda de pesquisa acadêmica. Então, eu acho que na academia o nosso propósito não deveria focar no que a conjuntura requer, mas sim em determos um certo recuo acadêmico, um entendimento crítico de grandes tendências independentemente do que a mídia requer ou do que a conjuntura requer.

\section{RM}

Podemos agora entrar no debate de como se faz pesquisa e os desafios a partir disso. Todas as pesquisas acadêmicas têm suas dificuldades e peculiaridades. Em se tratando do mundo muçulmano, o que o senhor destacaria?

\section{NM}

A primeira grande dificuldade é a falta de transparência e a falta de acesso às informações. É muito difícil fazer uma pesquisa sobre o mundo árabe muçulmano de longe. Os websites oficiais, as agências dos ministérios e os jornais são péssimos, praticamente em todo o mundoárabe e muçulmano. Não há dados reais, a não ser os de propaganda institucional, e os textos e links não estão disponíveis todo o tempo. Então a primeira grande dificuldade para fazer pesquisa e trabalho de campo no mundo árabe muçulmano é a falta de transparência e a falta de disponibilidade de material. A segunda dificuldade, que é decorrente desta falta de transparência, é a falta de acesso às pessoas quando o pesquisador vai para um lugar no mundo. As pessoas não se sentem muito à vontade para falar - e quando falam - falam uma língua oficial, uma linguagem oficial, um discurso oficial.

Quando se faz entrevista não é apenas para se ter acesso ao que é oficial. Para o acadêmico brasileiro, há uma terceira dificuldade que é a língua árabe, são poucos os institutos, no 
Brasil, que ensinam língua árabe. Porém, mesmo que algumas entrevistas possam ser feitas em inglês ou em francês, mesmo se alguma imprensa possa ser publicada em inglês ou em francês, o dia a dia ocorre em árabe. Sem dominar o árabe a pesquisa fica comprometida. Assim, somada à dificuldade inicial das pessoas que relutam em oferecer entrevistas, não falar o árabe prejudica enormemente o acadêmico brasileiro.

\section{RM}

Exatamente, a próxima pergunta que eu ia fazer era a dificuldade de fazer o trabalho de campo e a dificuldade da língua. Somado a essas dificuldades, tem o problema do financiamento. Para manter oulevar o pesquisador ao seu trabalho de campo, da perspectiva do Brasil, teria um custo alto. Como o senhor vê essa dificuldade do financiamento neste caso?

\section{NM}

Eu atuei no Brasil, no governo Lula, não no governo Dilma. Então no governo Lula, eu nunca tinha experimentado o Brasil com tantos recursos para se fazer pesquisas, para fazer pesquisas de campo, para viajar e para organizar conferências. Não estou aqui de forma alguma querendo entrar em discussões de política brasileira. 0 que eu estou dizendo é que há alguns anos, atrás, na década passada, no Brasil, havia muitos recursos para fazer pesquisa de campo, sem limitações. O CNPq tinha aquelas vertentes de financiamentos, como bolsa sanduíches para jovens pesquisadores, eu mesmo mandei vários alunos para alguns países árabes, e aquelas linhas de financiamentos para jovens pesquisadores mais estabelecidos, existiam financiamentos para pesquisadores entrarem com suas linhas de pesquisas e receberem apoio financeiro, razoável, para fazer suas pesquisas de campo. Eu sei que a realidade mudou, de maneira substancial, com a crise. E isso, sem dúvida, dificulta bastante o trabalho do pesquisador. Não se pode fazer pesquisa de campo sem passar uma temporada no local, conhecer as pessoas, estabelecer contatos e conseguir entender os códigos locais. Eu concordo que sem recursos financeiros isso se torna realmente muito mais difícil.

\section{RM}

Agora Nizar, podemos voltar um pouco na questão da religião, o Islã. Como o pesquisador tende a lidar com essa questão? Por que existe o pesquisador que está interessado no Oriente Médio e mundo muçulmano, mas não necessariamente no Islã. Pode-se olhar a relação de poder, a diplomacia e aspectos não necessariamente culturais, por exemplo. No entanto, sabemos que a religião faz parte das relações sociais e está sempre presente. Então isto às vezes é uma variável que dificulta bastante o trabalho de pesquisa neste 


\section{entrevista}

campo. Por outro lado, temos aqueles pesquisadores que estão exatamente interessados em estudar o Islã, pensar o Islã, e toda sua capilaridade social e política. Em sua opinião, como a religião interfere nesses trabalhos de pesquisa sobre o Oriente Médio e mundo muçulmano?

\section{NM}

Devo admitir que este tipo de dificuldade que você menciona aqui deve ser uma dificuldade do pesquisador brasileiro, pois recebemos o tempo todo aqui muitos pesquisadores europeus e norte-americanos, que trabalham com foco no Islã, na religião muçulmana ou no Islã político. Algumas vezes são pesquisadores que vem para visitas, outras vezes, vem para passar uma temporada, algumas semanas ou mesmo alguns meses. Então realmente pelo menos aqui no Marrocos e aqui na Universidade não temos problemas com isso, tem até um mestrado de estudos religiosos na qual admitimos alunos internacionais, no qual há alunos internacionais matriculados. Pode ser que haja uma certa postura defensiva dos muçulmanos sobre sua própria religião, pode ser que haja uma certa desconfiança das autoridades para saber quem é essa pessoa que se interessa pela região. Principalmente agora, com essa onda de fenômeno societal desses indivíduos que nascem no Ocidente e se convertem à religião muçulmana, mas entram em organizações como o Estado Islâmico e fazem atentados terroristas de grandes proporções. Então existe essa preocupação em não alimentar esse tipo de clientela, mas existe também o interesse em discutir e apresentar a religião sem esse modo de violência e sim como um modo de viver, uma opção pessoal, uma opção de sociedade, dependendo dos grupos com os quais se conversa.

\section{RM}

Nizar, você mencionou pesquisadores ocidentais interessados em estudar o mundo, você poderia falar de algo que diferencie o pesquisador brasileiro? Na sua opinião - nós os brasileiros - nos diferenciamos de alguma maneira neste universo de pesquisa, por exemplo, se comparado, pelo menos, com a América Latina? Você percebe alguma tradição que nos diferencia, uma escola ou algo neste sentido?

\section{NM}

Não me parece existir uma escola brasileira de estudos do Oriente Médio, não existe algo que diferencie o Brasil dos demais pesquisadores sobre o Oriente Médio, inclusive porque boa parte da literatura e da discussão bibliográfica que acontece no Brasil faz referência aos grandes debates que existem na Europa ocidental e na América do Norte. Os autores que são utilizados no Brasil, salvo algumas exceções locais, refletem e seguem as grandes linhas do debate internacional. Não me parece haver uma escola brasileira de estudos do 
Oriente Médio. No entanto, há um potencial no Brasil que não é explorado, que poderia ser interessante justamente para criar uma escola brasileira no campo das Relações Internacionais. Eu me refiro aqui às grandes comunidades de descendentes tanto de árabes quanto de judeus que moram no Brasil, então são brasileiros de várias gerações, que às vezes trabalham com questões relativas ao Oriente Médio e que poderiam trazer uma bagagem que se diferencie do peso do Orientalismo, como definido por Edward Said, que existe em muitas partes da academia ocidental. Mas também, ao mesmo tempo, que se diferencie de uma aproximação muito romântica do mundo árabe muçulmano, que também não reflete em nada o que acontece na região. Parece que este potencial que há no Brasil, e em alguns outros países da América Latina, poderia ser um asset como se diria em inglês, para desenvolver na academia brasileira estudos sobre o mundo árabe muçulmano. Que eu saiba me parece ainda não existir essa escola que o diferencie. Posso estar enganado, por não conhecer publicações mais recentes sobre o assunto, mas que eu saiba ainda não existe essa escola brasileira diferenciada das demais.

\section{$\mathbf{R M}$}

Algo que eu acho curioso e mesmo inevitável aqui no Brasil, principalmente dentro das Ciências Sociais, é a tradição marxista bastante forte e muito enraizada. Na sua opinião, existiria uma contribuição dentro o marxismo sobre os estudos sobre o Oriente Médio e mundo muçulmano?

\section{NM}

Acho que a tradição marxista até no Brasil tem sido ultrapassada dentro da academia. Essa tradição pode ter estabelecido alguns laços especiais nas décadas de 60, 70 e 80 do século passado com o mundo árabe e muçulmano, principalmente, incluindo aqui, Turquia, Irã e Israel. Mas me parece que hoje na academia, tanto no Brasil como no resto do mundo, as vertentes marxistas perderam um pouco da sua influência, do seu impacto para orientar os debates acadêmicos. Nas Relações Internacionais, no Brasil, as últimas contribuições marxistas são um pouco antigas, que eu saiba. Parece que as contribuições mais recentes não se encaixam bem nesta vertente marxista. E essa linha marxista não seria favorável, por exemplo, aos estudos da religião, das instâncias da religião, do mundo religioso, o que pode até ser um empecilho para uma compreensão mais aprofundada da região feita pela academia brasileira, no Brasil. Você acha que ainda existe marxismo na academia brasileira?

\section{RM}

Eu acho que se existe em algum lugar no mundo, acho que ainda é aqui no Brasil. Muitos pesquisadores egressos do marxismo se interessam por Edward Said, por exemplo. E 
pelo Said se pode pensar o imperialismo, conflitos - como os de Israel e Palestina - e até mesmo entrar em temas culturais por essa chave orientalista. E aí eu posso também emendar outra pergunta. Muitas vezes, a agenda de pesquisa depende do orientador, então, às vezes, a pesquisa se desdobra a partir da posição dos orientadores que estão disponíveis. Será que isso também não direciona ou até mesmo limita a agenda de pesquisa?

\section{NM}

Eu acho que este é um risco que existe em todos os círculos acadêmicos incipientes, que estão dando os seus primeiros passos. Eu me lembro que no decorrer da década passada, Peter [Demant] e eu éramos de linhas distintas, mas nunca evitávamos trabalharmos juntos, de participar de mesas juntos, de chamar um ao outro para bancas, pois ambos tínhamos um entendimento do papel do acadêmico, de que não é de criar uma "igrejinha" - por falta de uma expressão melhor por parte de um judeu e de um árabe. Nosso entendimento de academia era criar um grupo que deveria crescer e uma massa crítica, que essa sim poderia providenciar e se aprofundar nesses debates. Mas naquele momento, na década passada, era o momento de formar uma comunidade e uma massa crítica. E eu acho que esse é o papel do acadêmico, e não estou falando aqui de um mundo ideal. Eu estou convencido que existem várias pessoas (eu trabalhei com muitas pessoas na academia brasileira) com essa mesma convicção de criar uma massa crítica e depois criar 'escolinhas' que seguem essa ou outra linha. Parece-me que o Brasil ainda está em fase da consolidação e o papel dos professores deveria ser de orientar as pesquisas, quaisquer pesquisas, e julgar o trabalho em cima do valor do trabalho - e não sobre como nós gostaríamos que o trabalho fosse orientado. Por isso que o papel do orientador, numa academia incipiente sobre estudos sobre o Oriente Médio, como é o caso da academia brasileira, seria o de criar um grupo de pesquisadores que possa vir a deslanchar no futuro, ao invés de entrar nestas lutas desnecessárias que acabam não levando a nada.

\section{RM}

Na ideia de fomentar a pesquisa e de ter interlocução, muitos pesquisadores sentem uma certa solidão nesse trabalho, porque se tem dificuldade de encontrar interlocutores ou outros pesquisadores com interesse de pesquisa parecido. Nesse sentido, como você avalia o papel dos grupos de pesquisas, dos congressos ou mesmo revistas temáticas sobre o Oriente Médio. Você teve experiências deste tipo?

\section{NM}

Eu acho isso fundamental, para criar essa massa crítica você tem que ter um ambiente para desenvolver esse tipo de debate, como conferências, associações e grupos de 


\section{entrevista}

pesquisas, justamente para romper esse isolamento do pesquisador. É preciso juntar as forças para poder, justamente, divulgar bibliografias, tornar o debate presente de maneira sistemática, convencer bibliotecas a assinar revistas e conseguir convencer os centros de financiamentos a financiar essa pesquisa. Se você for mandar, por exemplo, seu projeto de pesquisa sobre o Irã para um pesquisador que não tem ideia sobre o Irã, ou um avaliador anônimo da Capes ou do CNPq, provavelmente o retorno por sua pesquisa vai ser muito menos positivo e menos interessado do que se tivesse sido enviado para um pesquisador que tem interesse na região. E para que esse pesquisador [interessado na região] possa ser um avaliador da Capes ou do CNPq é preciso justamente criar essa massa crítica e romper com esse isolamento. Então me parece que esse é um passo fundamental para aumentar a capacidade da academia brasileira de ter uma contribuição mais original e mais autônoma sobre as questões do Oriente Médio. Isto sem necessariamente ignorar as dificuldades ou as divergências sobre as diversas linhas de pesquisa.

Existem algumas conferências que acontecem nos Estados Unidos e na Europa ocidental que poderiam ser relevantes e importantes para o pesquisador brasileiro se integrar dentro desse círculo e se inteirar dos debates que existem. Mas, obviamente, se o pesquisador brasileiro vai pedir financiamento para ir a uma conferência sobre o mundo árabe muçulmano, o avaliador da Capes ou do CNPq não vai entender a validade ou a relevância dessa conferência. Por isso, mais uma vez, está posta a importância de criar e expandir essa massa crítica nos estudos e análises das questões relativas ao Oriente Médio e ao mundo árabe e muçulmano.

\section{RM}

Eu também considero isso muito importante, por isso nosso esforço com a revista Malala e o Peter também com o grupo de trabalho na USP sobre o Oriente Médio e Mundo Muçulmano (GT OMMM). Mas olhando pela perspectiva também do pesquisador, acho que há uma dificuldade para desenvolver isso, que é um pouco oriunda da lógica produtivista. Quer dizer, você precisa publicar, você tem prazos rígidos, você tem um mês de trabalho de campo, ou seis meses para escrever um artigo, etc. E, às vezes, isso se torna algo tão presente que se torna mais importante que a própria pesquisa. 0 foco vira o publicar, o importante torna-se cumprir os prazos. Como você vê essa burocratização da pesquisa?

\section{NM}

Essa, como dizem justamente os marxistas, é a comodificação do conhecimento: quando o conhecimento se torna uma commodity, é isso que estamos vendo em toda nossa vida acadêmica. Os números, quantos artigos que você publicou? Qual é o impact factor? Isso é tão empobrecedor para a academia... Eu admito realmente a importância de critérios 
de qualidade para assegurar padrões de qualidade na produção acadêmica. Acho que se aprende muito com isso. Eu fico triste que muitas importantes revistas na área da Ciência Política e das Relações Internacionais no Brasil estão sendo publicadas em inglês. Eu fico me perguntando, como aquele jovem estudante de Ciências Sociais, por exemplo, no interior do Brasil, com grande potencial de fazer contribuições no futuro próximo, como ele vai crescer e se firmar na área se não há revistas na língua dele ou dela? Obviamente, essa padronização do modelo de produção de conhecimento - no qual todos temos que ler as mesmas coisas, refletir sobre os mesmos assuntos, nos candidatar para as mesmas bolsas e escrever da mesma maneira - é muito empobrecedor. Se existe uma riqueza da academia - e a academia brasileira, me parece, foi muito boa nisso por muitos anos - foi justamente a de permitir um certo arco-íris, um grande leque de opções e permitir que o debate aconteça. Eu lembro que, depois de 11 de Setembro, o meu querido amigo Eduardo Viola quando ia para as conferências e defendia uma posição pró-EUA, as pessoas diziam "que coragem do Eduardo". Eu pensava: se não se pode defender uma posição no mundo acadêmico, onde se vai poder defender uma posição de dissidência? A academia é o espaço para essa dissidência.

Eu fico triste diante dessa homogeneização dos padrões. Dessa homogeneização do modo de produção do conhecimento, homogeneização do modo de pensar, que acaba sendo empobrecedor. Temos que encontrar um meio termo entre estabelecer um alto padrão de qualidade, liberdade no modo de pensar e transparência no uso dos recursos e fundos de pesquisa. Eu sei de pesquisadores que não usam seus fundos de pesquisas para os quais esses fundos foram estabelecidos. Eu acho que deve haver critérios estritos para isso, mas ao mesmo tempo isso não pode empobrecer o debate acadêmico e reduzi-lo a uma questão quantitativa, a quantos artigos publicados, em qual revista ou qual o impact fator. Se for assim, estamos decretando o fim da inovação no pensamento acadêmico.

\section{RM}

Seria interessante, se possível, que o senhor falasse um pouco sobre o Marrocos. O que o levou a ir ao Marrocos. Você pensa em voltar ao Brasil? Enfim, qual seu balanço desta experiência.

\section{NM}

O que me trouxe ao Marrocos foram tanto questões pessoais, de família, quanto profissionais. Fechei um ciclo produtivo no Rio de Janeiro. Eu estava me interessando por temas desta região. Mas também tinha minha filha que nasceu no Brasil, eu não conseguia falar em árabe com ela, então eu e minha esposa pensamos que devíamos passar uma temporada no Marrocos, permitir a ela aprender o árabe, conhecer a outra metade dela. Ela 


\section{entrevista}

já conhecia bem o Brasil, então pensamos que seria bom ela conhecer o Marrocos. Motivos diversos me levaram a voltar para o Marrocos. Nesse momento eu tenho uma agenda de pesquisa um pouco reduzida, porque sou decano de uma faculdade, então tenho uma responsabilidade administrativa mais intensa. Mas isso não me impede de fazer pesquisa, porque é isso que mais me atrai e me interessa. Meus dois principais assuntos de pesquisa, atualmente, estão nas Teorias das Relações Internacionais. Eu estou fechando um livro, em parceria com duas colegas, sobre as contribuições do debate Global South para a teoria das Relações Internacionais. Eu sou co-editor desse livro, com minha contribuição sobre a questão do conceito da guerra e da violência produzidos pelo Global South. Outra área de interesse é como a imigração representa um desafio para as categorias tradicionais das Relações Internacionais. Eu estou terminando um capítulo sobre a geopolítica e a questão da imigração e estou usando a questão do espaço no debate sobre imigração.

Se vou voltar ao Brasil? O Brasil tem um lugar especial no meu coração e na minha cabeça, mas nos próximos anos não vejo possibilidade de voltar ao Brasil. Contudo, se na minha idade eu aprendi alguma coisa foi nunca dizer "nunca" nem também dizer "sempre". Então estou aberto e vamos ver o que o futuro esconde. 